\title{
Analysis on corrosion fatigue cracking mechanism of 17-4PH blade of low pressure rotor of steam turbine
}

\author{
Yuwei Wei ${ }^{1}$, Yongjun $\mathrm{Li}^{1}$, Jiafeng Lai ${ }^{1}$, Qinxin Zhao ${ }^{1}$, Lili Yang ${ }^{1}$, Qingyu Lin ${ }^{1}$, and Xiaolin \\ Wang $^{1}$
}

${ }^{1}$ Affiliation not available

May 5, 2020

\begin{abstract}
Abstract: The causes of many blade fractures of a steam turbine in a power plant were analyzed by means of macro analysis, mechanical examination, metallographic examination, SEM and X-ray fluorescence spectrum analysis(XRF). The results show that the blade cracks due to corrosion fatigue. $\mathrm{Cl}-, \mathrm{K}+$, etc. react with the turbine blades in the steam environment in physical, chemical and electrochemical ways, causing local spot corrosion on the blades, forming corrosion pits.In addition, the steam condensate has an erosion effect on the blades, both of which form a corrosion fatigue source. The autocatalytic process of block cell is formed when $\mathrm{Cl}-, \mathrm{K}+$, etc. react with the turbine blades. Under the action of complex load, the current density i of activation dissolution of metal can be expressed as a function of complex stress state .Crack growth has an important relationship with stress, depth and width of corrosion pits. The larger the width of corrosion pit is, the deeper the depth is,

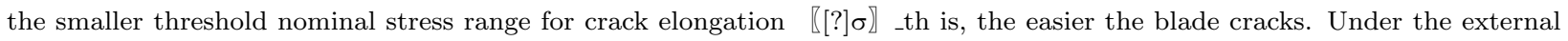
conditions of complex alternating stress formed by tensile force, bending force, torsion force and exciting force, the complex alternating stress directly promotes the crack propagation until the fracture failure. Keywords:XRF; Corrosion fatigue;Corrosion pit;Threshold nominal stress range for crack elongation $\llbracket[?] \sigma \rrbracket$ _th;Complex alternating stress
\end{abstract}

Analysis on corrosion fatigue cracking mechanism of 17-4PH blade of low pressure rotor of steam turbine

Yuwei Wei ${ }^{1,2 *}$, Yongjun $\mathrm{Li}^{2 *}$, Jiafeng $\mathrm{Lai}^{3 *}$, Qinxin Zhao ${ }^{1}$,Lili Yang ${ }^{4}$,Qingyu Lin ${ }^{2}$, Xiaolin Wang $^{2}$

1.Key laboratory of Thermo-Fluid Science and Engineering of MOE ,Xi'an Jiaotong University, Xi'an,710049, China;

2.Guangxi Special Equipment Supervision and Inspection Institute, Nanning, 530219, China

3. College of Petroleum and Chemical Engineering,Beibu Gulf University,Qinzhou, 535000,China

4. School of Electronic and Information Engineering,South China University of Technology,Guangzhou, 510006, China

*These authors contributed equally to this work.

Abstract: The causes of many blade fractures of a steam turbine in a power plant were analyzed by means of macro analysis, mechanical examination, metallographic examination, SEM and X-ray fluorescence spectrum analysis(XRF). The results show that the blade cracks due to corrosion fatigue. $\mathrm{Cl}^{-}, \mathrm{K}^{+}$, etc. react with the turbine blades in the steam environment in physical, chemical and electrochemical ways, causing local spot corrosion on the blades, forming corrosion pits.In addition, the steam condensate has an erosion effect on the blades, both of which form a corrosion fatigue source. The autocatalytic process of block cell is formed when $\mathrm{Cl}^{-}, \mathrm{K}^{+}$, etc. react with the turbine blades. Under the action of complex load, the current density $i$ 
of activation dissolution of metal can be expressed as a function of complex stress state Crack growth has an important relationship with stress, depth and width of corrosion pits. The larger the width of corrosion pit is, the deeper the depth is, the smaller threshold nominal stress range for crack elongation $\sigma_{\text {th }}$ is, the easier the blade cracks. Under the external conditions of complex alternating stress formed by tensile force, bending force, torsion force and exciting force, the complex alternating stress directly promotes the crack propagation until the fracture failure.

Keywords:XRF;Corrosion fatigue;Corrosion pit;Threshold nominal stress range for crack elongation $\sigma_{\mathrm{th}}$;Complex alternating stress

\section{Introduction}

Among all failure accidents in the power plant, turbine blade failure accounts for the largest proportion. Fatigue fracture is the most common type of turbine blade failure. The working condition and environment of steam turbine blades are very bad, mainly in stress state, working temperature, environmental medium and so on. When the blade breaks, the fracture often occurs in the middle and root of the blade ${ }^{[1]}$. In the working process, the turbine blades bear the tensile stress caused by the centrifugal force when the rotor rotates, and the bending stress and torsion caused by the steam flow pressure; the excited vibration force of the blades will produce forced vibration, even cause resonance, and the complex alternating stress will eventually lead to the fatigue fracture of the blades ${ }^{[2-3]}$. The working temperature of each stage blade of steam turbine is different. The temperature of the first stage blade is the highest (above 500), and then the temperature will be reduced gradually due to the steam working step by step, and the temperature will be reduced to below 100 until the last stage blade. During the operation of steam turbine, the steam is easy to condense into small water drops at the last stage blade. If there are corrosive elements in the steam, it will form electrolyte with water. It adsorbs on the surface of blade and forms micro cell, which causes electrochemical corrosion. These local corrosion points will become the weak points of blades, and the failure often originates from them. Xie Jianfeng ${ }^{[4]}$ analyzed the fracture failure of steam turbine blades in a petrochemical thermal power plant. The fracture of the blades was caused by fatigue. The fatigue source was located in the exhaust side of the blades, which suffered from high stress and strain, and formed a sharp groove at the edge of the blades due to cavitation, which changed the stress state of the blade surface, making the cracks easier appear and be growth. S. $\mathrm{Qu}{ }^{[5]}$ thinks that the reason of blade fracture is the stress concentration. With the gradual expansion of the crack, the blade finally breaks. Anson ${ }^{[6]}$ analyzed the vibration characteristics, frequency data and macro characteristics of imported $300 \mathrm{MW}$ and $600 \mathrm{MW}$ steam turbines, and summarized the failure forms of blades, roots and rims. B.M. Schönbauer ${ }^{[7]}$ found that the cracking of the blade of low pressure steam turbine was caused by stress corrosion through conventional detection technology and accident site exploration. Zhu Baotian et al. ${ }^{[8]}$ analyzed the fatigue life of the last stage $905 \mathrm{~mm}$ blade of the steam turbine, and thought that the factors affecting the life of the blade were the alternating stress, stable stress, surface corrosion pit and so on, such as exciting force, dynamic stress, bending stress, centrifugal force, low cycle and high cycle fatigue load.

Accident unit was put into operation in September 2016. The steam turbine (Model:CLN350-24.2/566/566 ) is supercritical, primary intermediate reheat, single shaft, single back pressure, wet condensing steam turbine produced by Harbin steam turbine works Co., Ltd., which has the operation capacity of steam extraction with heat supply. The unit has started 12 times since it was put into operation, and entered into overhaul in late June 2018.

The rated speed of the steam turbine is $3000 \mathrm{r} / \mathrm{min}$. The rated pressure in front of the main steam valve is $24.2 \mathrm{MPa}$, and the rated temperature is 566 . The pumping stage is 8 . The length of the last stage blade of the low pressure cylinder is $550 \mathrm{~mm}$.

The model of steam turbine supporting boiler is DG-1110/25.4-II1, manufactured by Dongfang Boiler Factory Co., Ltd. in April 2015, with design pressure 25.4MPa, design temperature 571, and cumulative operation 18000 hours. 


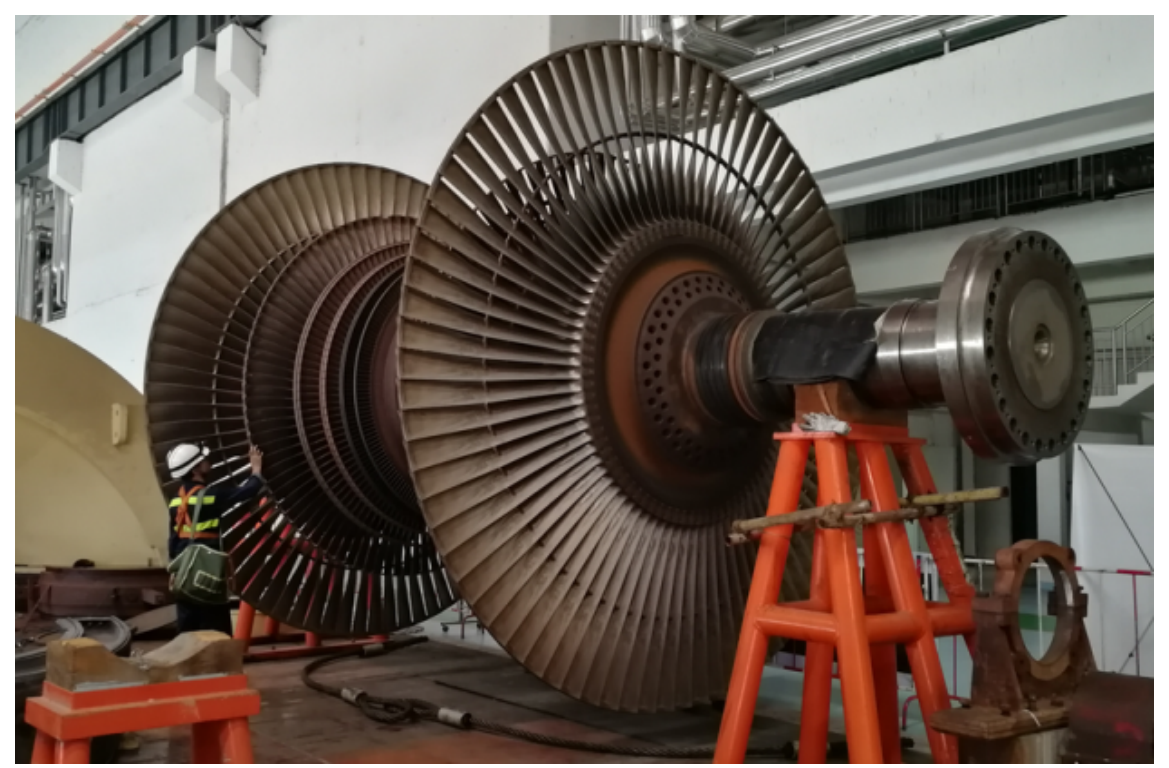

Fig. 1 The last stage blade

The blade with cracks is the second last stage blade of low pressure rotor of 350MW supercritical unit(Fig. 1 ), made of $17-4 \mathrm{PH}$ (China brand $05 \mathrm{Cr} 17 \mathrm{Ni} 4 \mathrm{Cu} 4 \mathrm{Nb}$ ), which is a martensitic precipitation hardening stainless steel with solution + aging. During the overhaul in July 2018, it was found that 80 of the 98 moving blades of the second last stage of low-pressure rotor had cracks near the root, near the top and in the middle of the blade back arc.

The cracking mechanism of the low-pressure rotor blades is analyzed in this paper in order to find out the causes of the defects and make preventive measures.

\section{Experimental procedures}

\subsection{Visual examination}

According to NB / T47013-2015 Nondestructive testing of pressure equipment, 100\% inspection was carried out for 5 -stage moving blades of low-pressure rotor by combining macroscopic inspection and magnetic particle inspection.

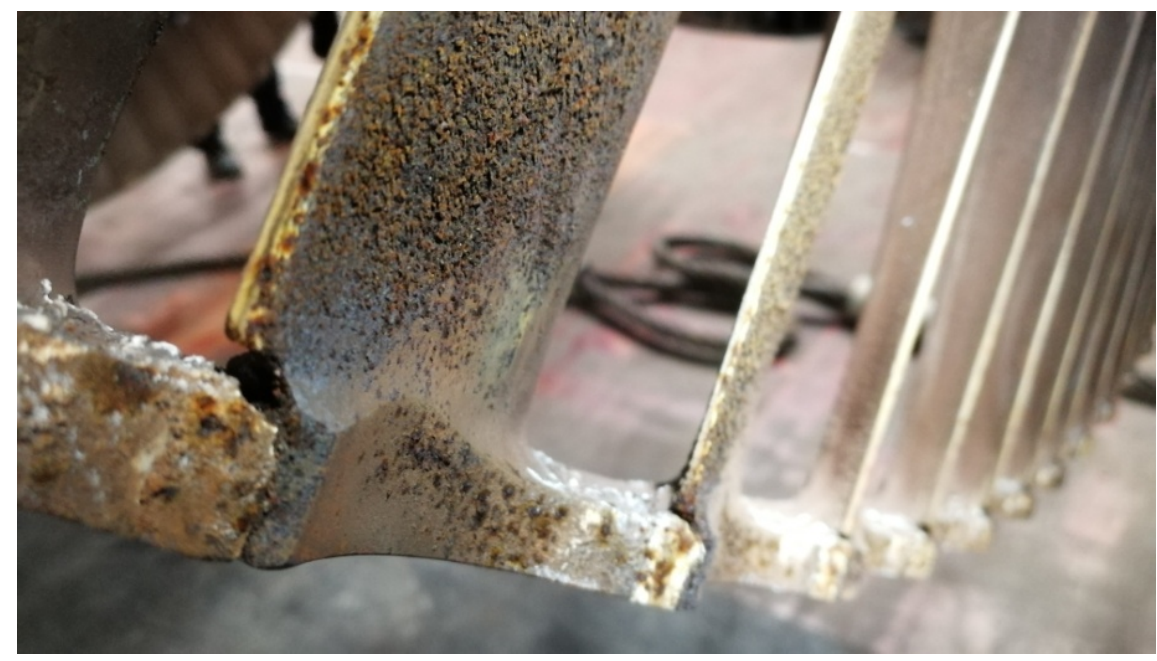




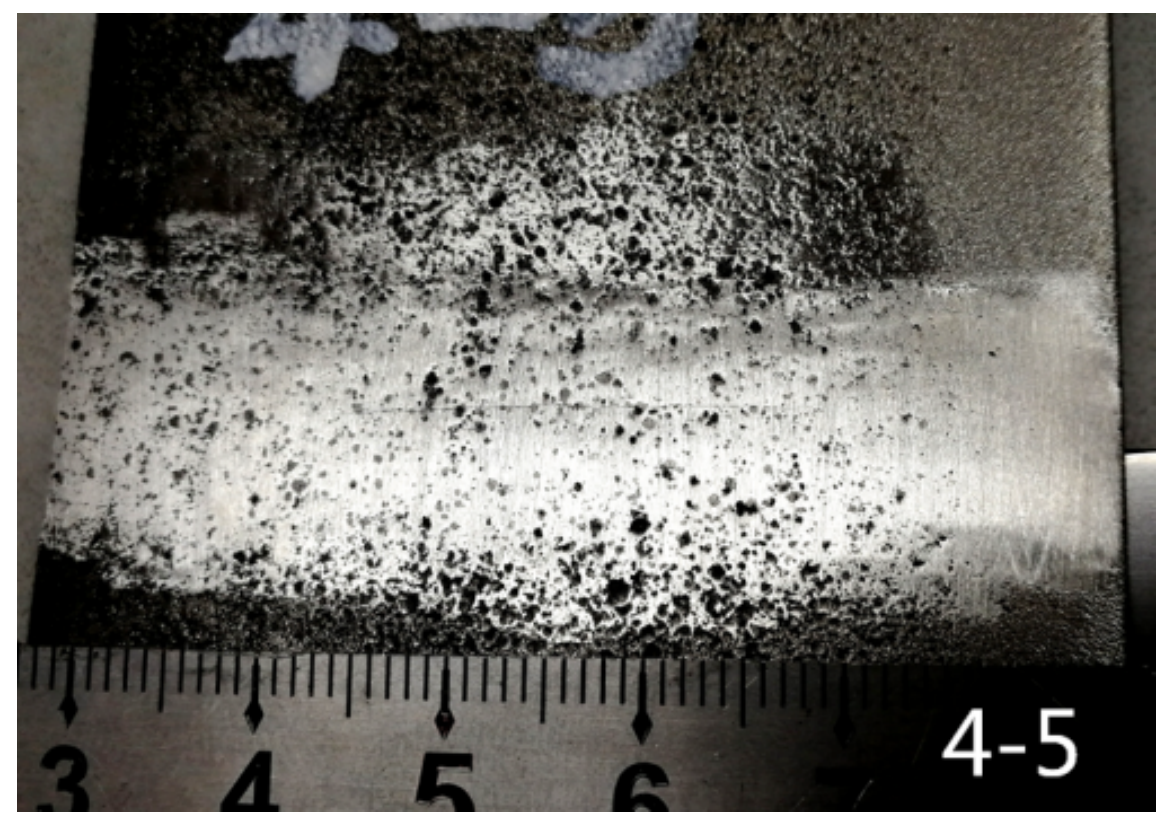

Fig. 2 Surface corrosion of last stage blade

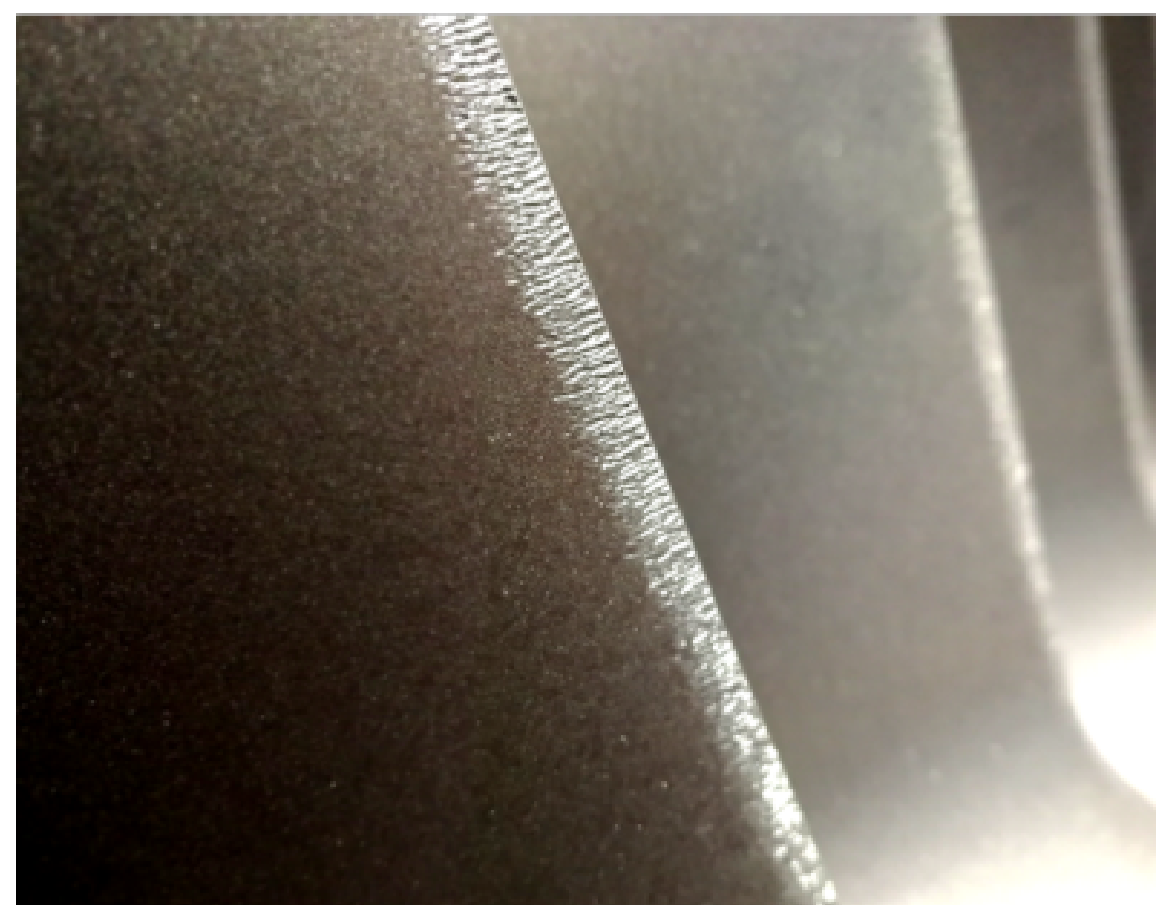

末级叶片 


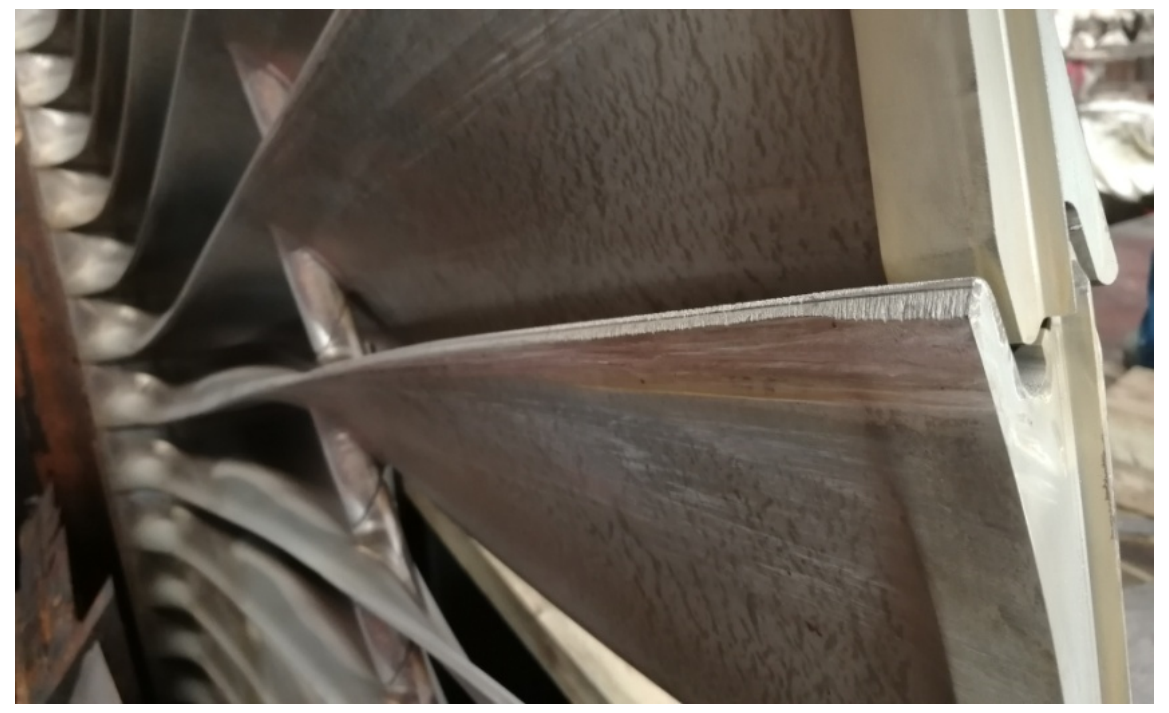

Fig. 3 Water erosion of last stage blade

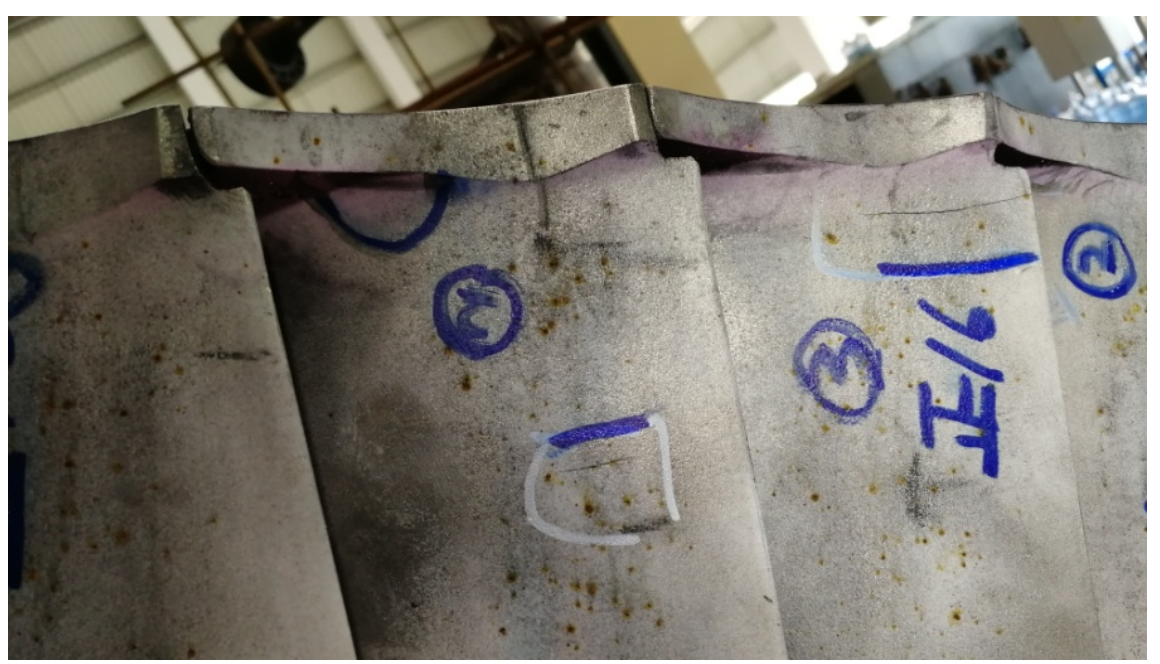



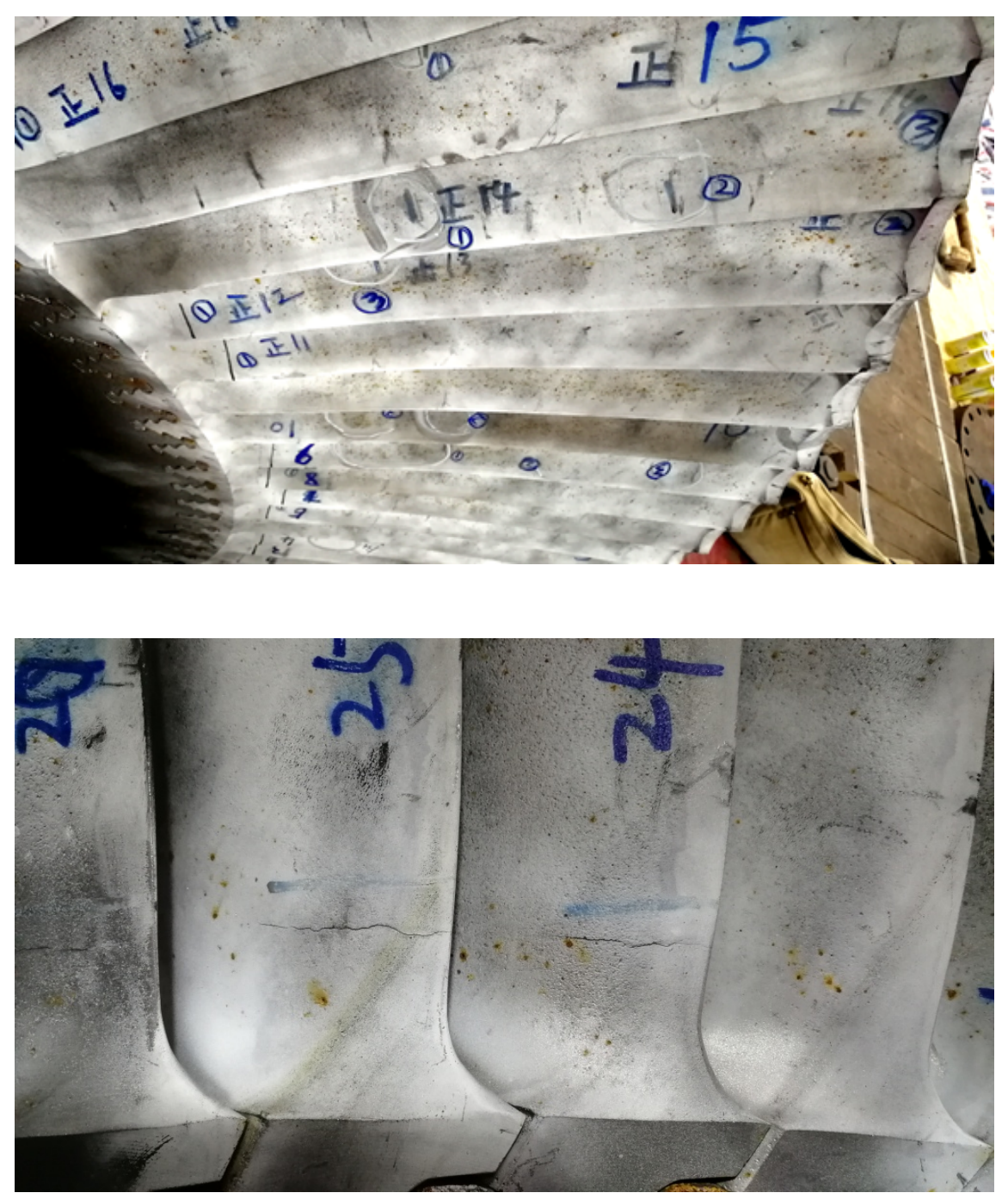

Fig. 4 A:Cracks on the top of blade,B:Cracks in the middle of blade,C:Cracks at blade root

Through inspection, it is found that there is corrosion of different severity on the surface of blades, and there are a large number of obvious corrosion pits, the second and last stage blades are the most serious. Water erosion was also found on the last stage blade (Fig. 3). The water erosion on the edge of the blade has both physical and chemical effects. The defect appears near the top of the inlet side and the root of the outlet side, with a depth of less than $1 \mathrm{~mm}$. There are 80 cracks near the root, near the top and in the middle of the blade back arc in 98 moving blades of the last stage of low pressure rotor. According to the location and general shape of the cracks, it can be divided into three types: the first type cracks of near root(Fig. 4 C): mainly distributed in the back root of the blade opposite to the steam face, the cracks are relatively obvious, some cracks are visible to the naked eye after sandblasting, and the trend is vertical to the direction of the maximum normal stress. The second kind of cracks in the middle of blade back arc(Fig. 4 B): the cracks are relatively thin, short and shallow, all appear on the back arc surface, which can be found through magnetic particle inspection, and the direction is perpendicular to the direction of the maximum normal stress. The third kind of near blade top crack(Fig. 4 A): mainly distributed in the variable cross-section of blade tip, and the direction of crack is generally perpendicular to the direction of maximum normal stress. This kind of crack is mainly found in the forward blade of the second last stage. 
In this paper, the broken 4 \# blade is taken as the research object.

\subsection{Chemical analysis}

According to GB / T4336-2016 carbon steel and low and medium alloy steel spark source atomic emission spectrometric analysis method (conventional method), the 17-4PH sample of the broken blade was analyzed by the spark source atomic emission spectrometer (OBLF GS1000 -II). The chemical analysis results of the cracked blade are listed in Table 1. The chemical composition of standard 17-4PH stainlesssteel from GB/T 8732 is given for comparison. It is found that the chemical composition of the blade is consistent with the design standard.

Table 1 Chemical composition of the investigated 17-4PH (mass\%).

\begin{tabular}{|c|}
\hline S Cl K \\
\hline 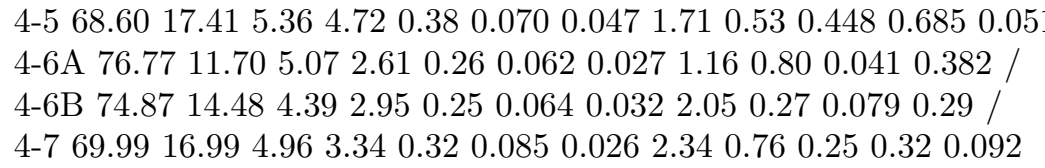 \\
\hline
\end{tabular}

The results show that the content of chemical elements in leaves is qualified.

\subsection{Mechanical analysis}

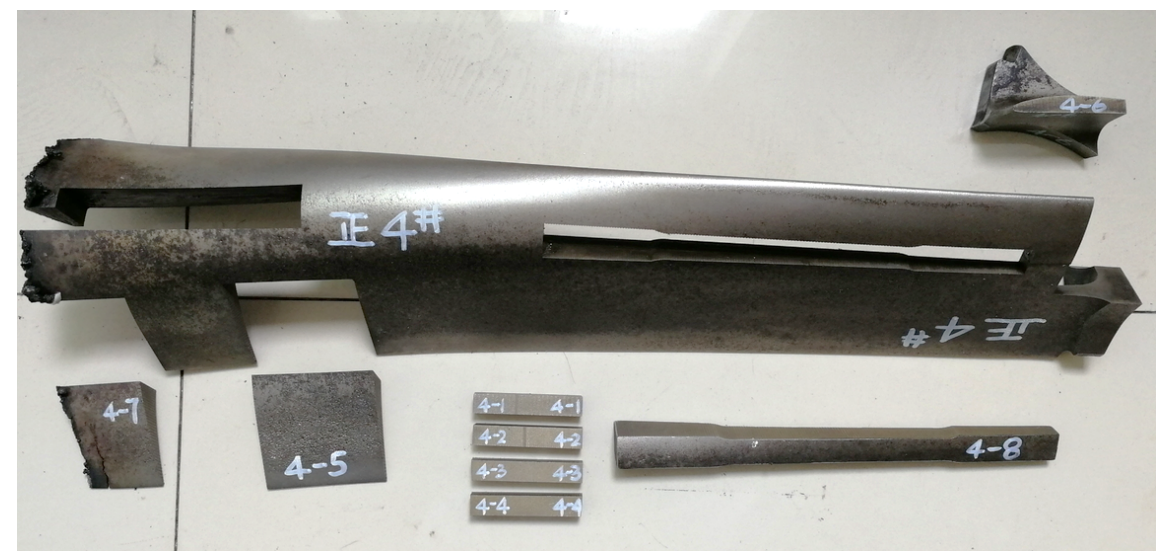

Fig. 5 Sampling(among them, 4-5 is the element analysis sample, 4-6 is the metallographic sample, 4-8 is the tensile sample, 4-1, 4-2, 4-3, 4-4 is the impact sample)

\subsubsection{Tensile test}

Sampling shall be carried out according to Fig.5 and GB /T228.1-2010metal material tensile test Part 1: room temperature test method, and the test shall be carried out with Metz microcomputer servo universal testing machine. Test results: the yield strength is $860 \mathrm{MPa}(755-890 \mathrm{MPa}$ as required by the standard), the tensile strength is $899 \mathrm{MPa}(890-1030 \mathrm{MPa}$ as required by the standard), the elongation after fracture is $18.9 \%$ ( $16 \%$ as required by the standard), and the area shrinkage is $62.7 \%$ (55\% as required by the standard).The tensile properties of these two samples are comparable with the specification requirements according to GB/T 8732. Tensile properties of the cracked blade are also in accordance with the design standard 。

\subsubsection{Impact test}

According to GB / T229-2007 Metallic materials Charpy pendulum impact test method , 4-1, 4-2, 4-3, 4-4 
impact specimens were tested with pendulum impact test machine. The test results show that very high impact toughness is up to $110 \mathrm{~J}$.

\subsubsection{Hardness measurements}

According to GB / T230.1-2018 Metallic materials Rockwell hardness test Part 1: test method, Rockwell hardness tester is used for testing. The test results show that the hardness value of the broken blade is $280-297 \mathrm{HB}$, which is qualified (the qualification standard is $277-321 \mathrm{HB}$ ).

\subsection{Fractography}

According to GB /T13298-2015 Test method for microstructure of metal, after mechanical polishing, picric acid + hydrochloric acid are used for erosion, and then metallographic analysis is carried out for the cracked blade section. The microstructure was analyzed by metallographic microscope and scanning electron microscope(SEM). The results(Fig. 6, Fig. 7 )show that the microstructure is low carbon martensite + dispersed intermetallic strengthening phase, the matrix structure is normal, and there are many fine branch cracks along the grain near the main crack.

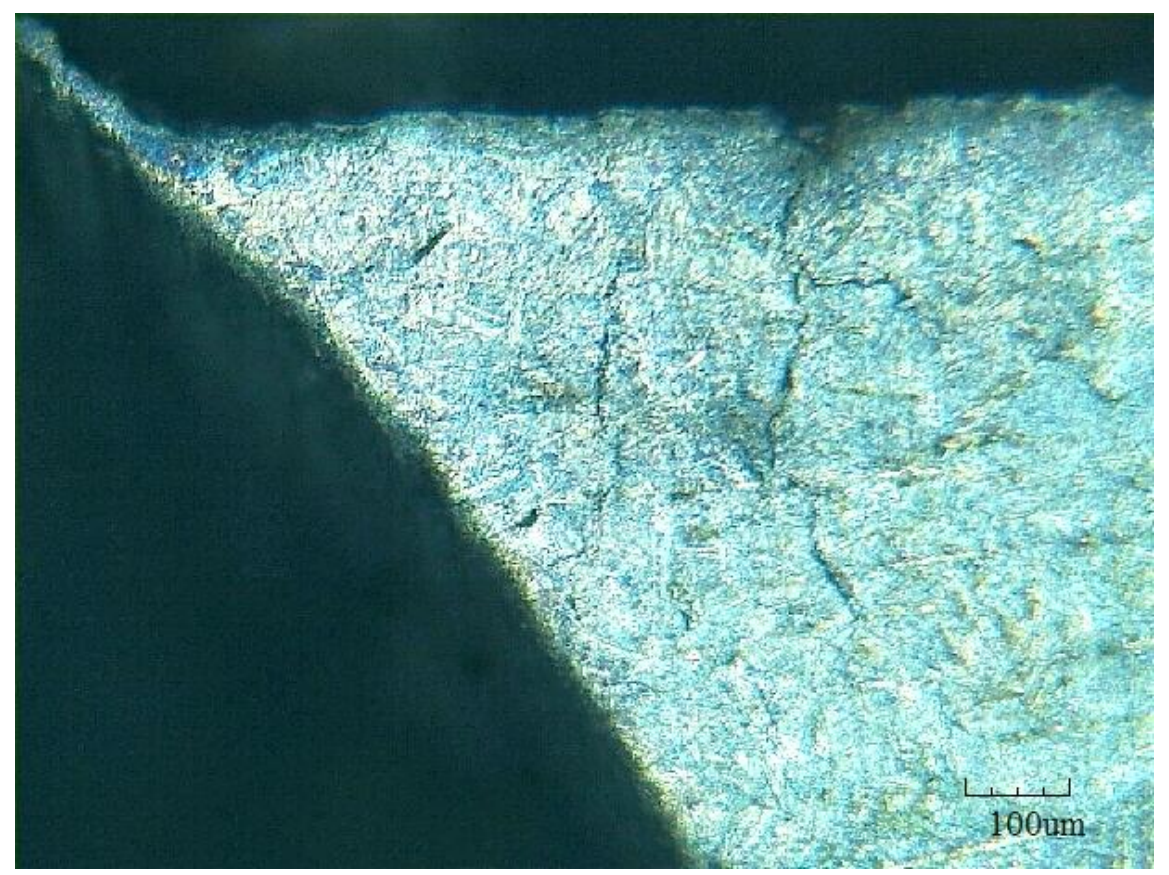




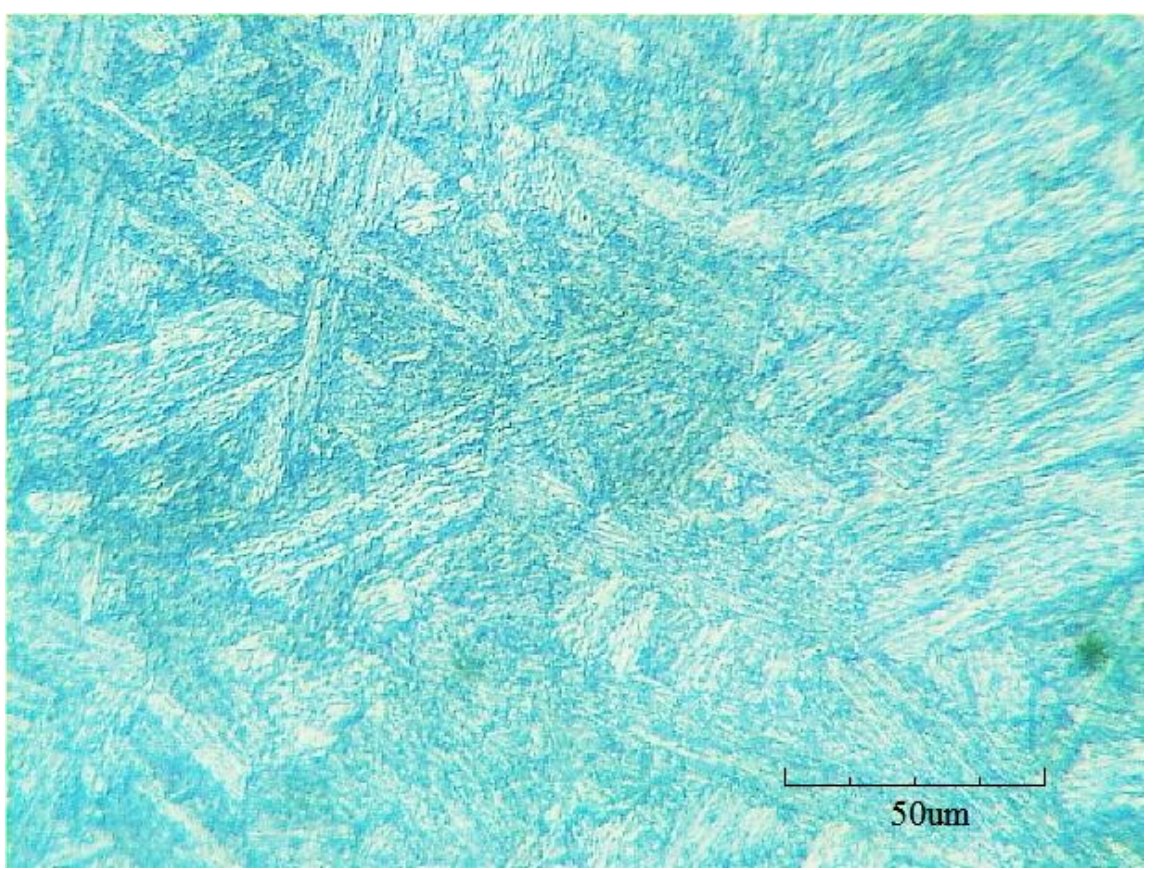

Fig. 6 Metallographic structure of 4-6b section

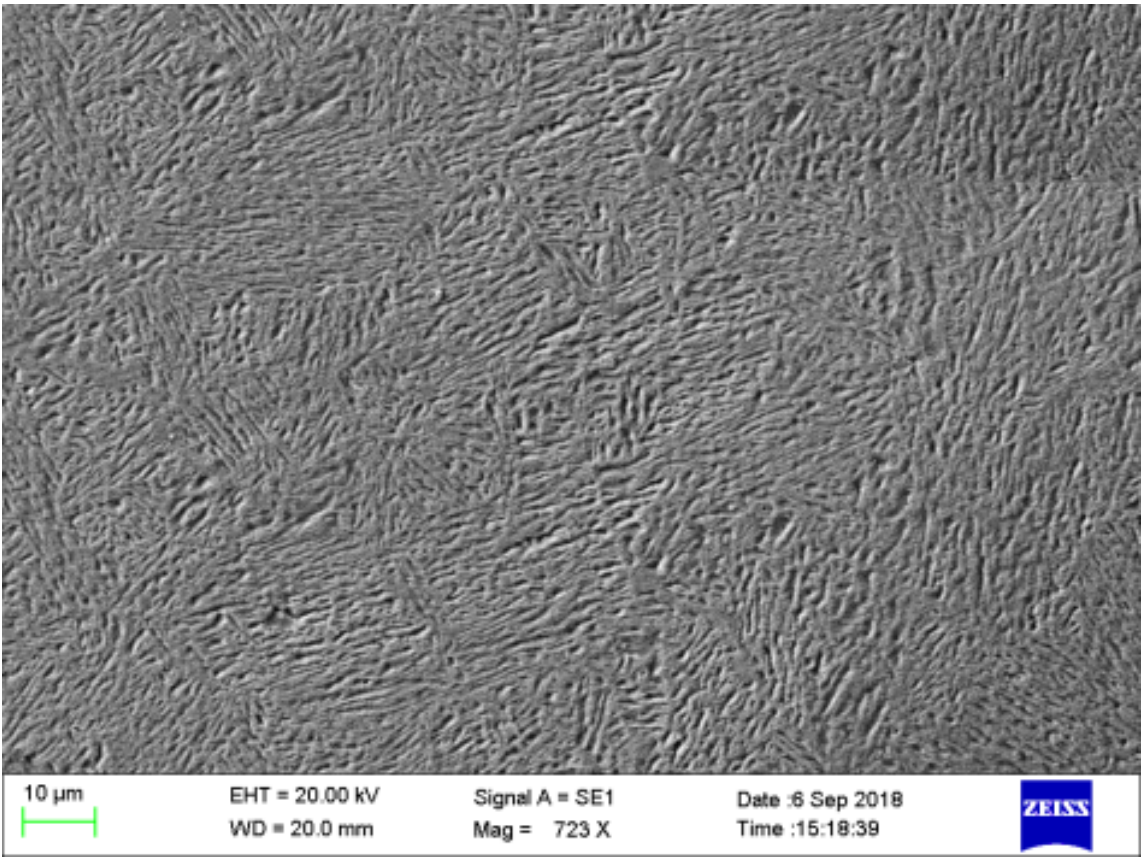




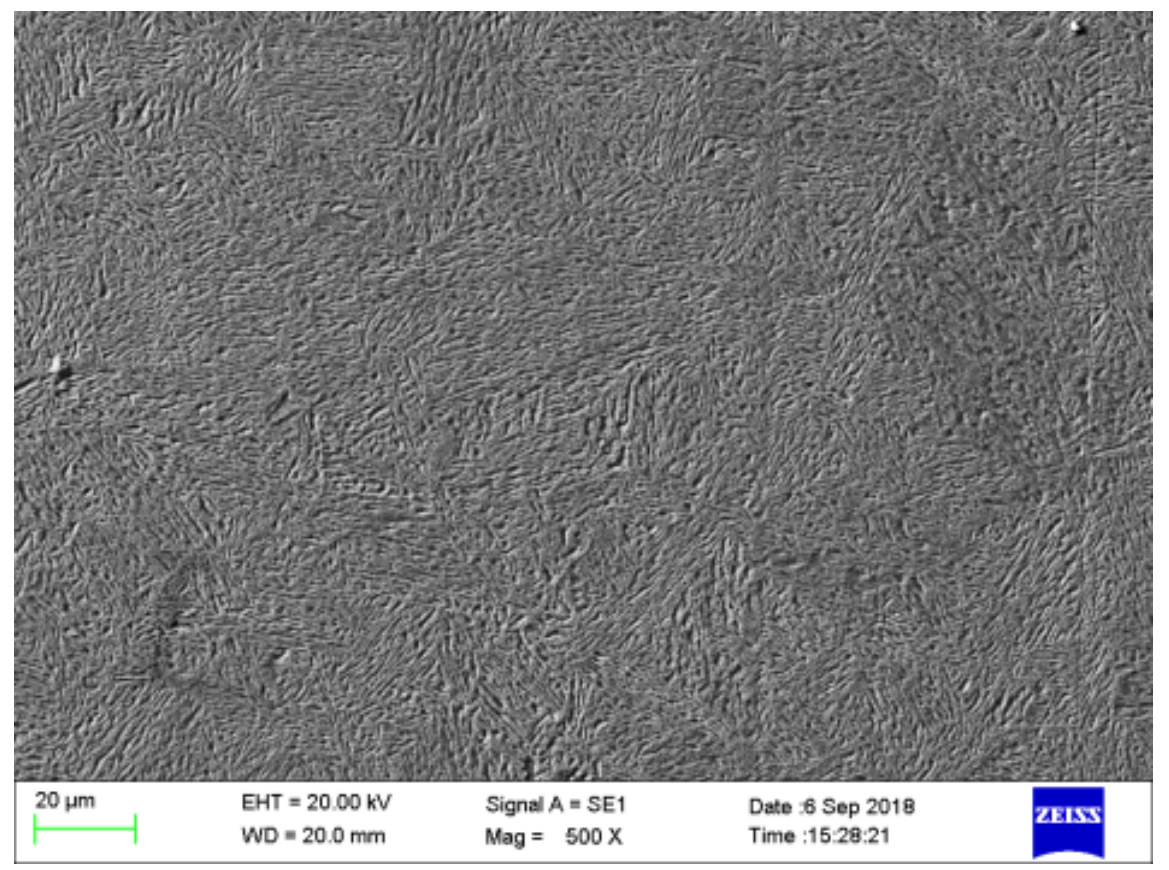

Fig. 7 Microstructure by SEM

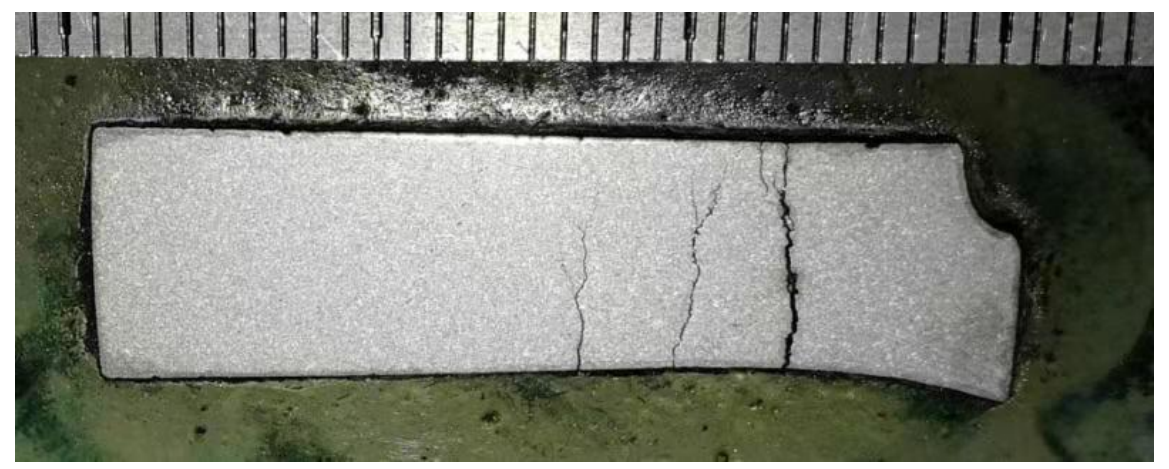

Fig.8 Macro crack morphology 

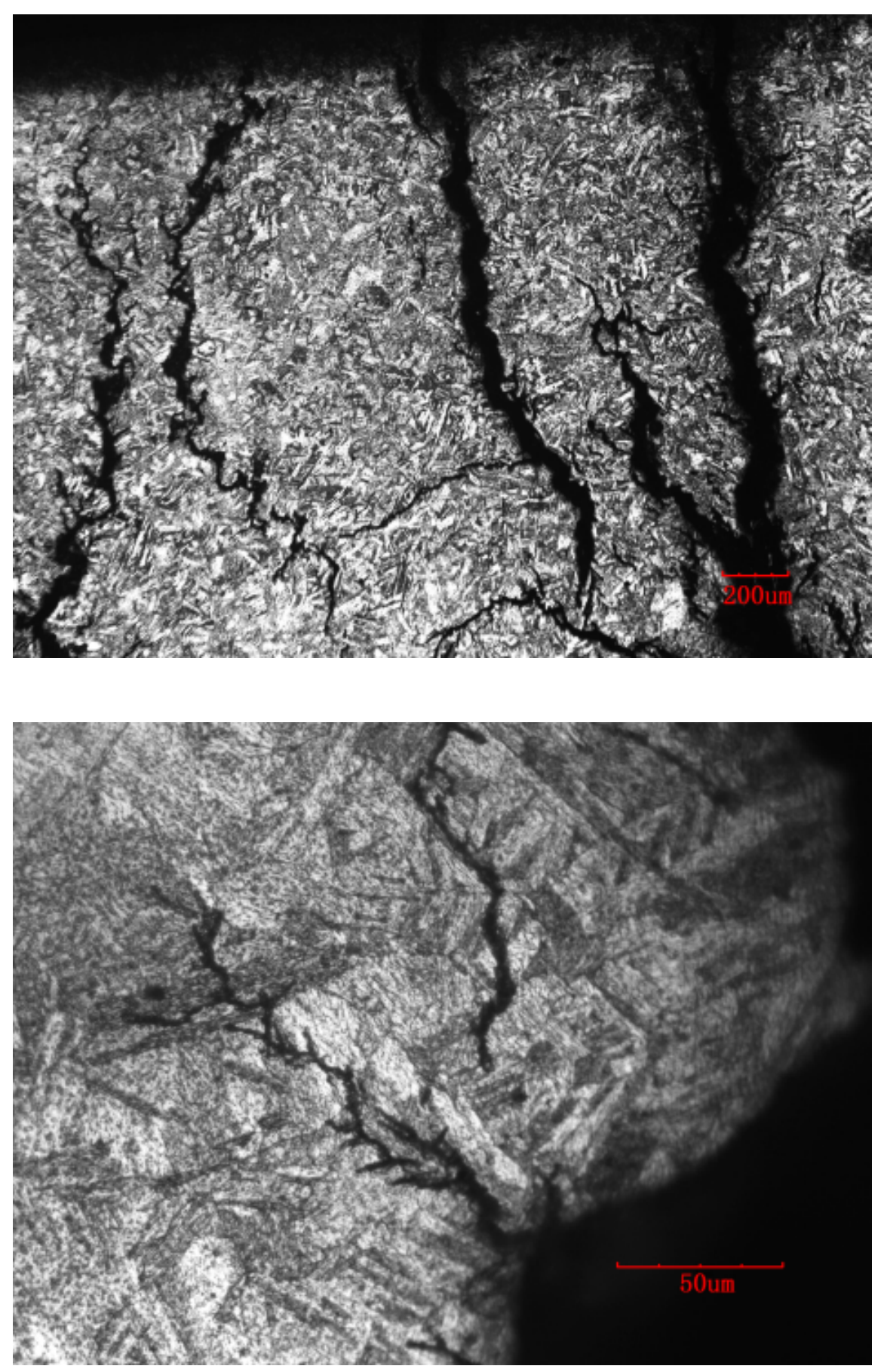

Fig.9 Microcrack morphology(Dotted area in Fig. 10)

As shown in Fig. 8, a large number of cracks $(1 \#, 2 \#, 3 \#)$ were found in the scanning area at low magnification. All the three cracks originate from the corrosion pit. However, the crack initiation and propagation direction are different. Both 1 \# and 2 \# cracks originate from the corrosion pits on the lower surface of the blade, and the cracks propagate to the upper surface, forming many directional dendritic cracks near the crack end. 3\# cracks are quite special. On the one hand, they start to expand upward from the origin of the 
lower surface, and on the other hand, many secondary cracks originate from the corrosion pits on the upper surface and expand downward. The reason of the secondary cracks on the upper surface is inferred: because the main cracks are $40 \mathrm{~mm}$ long and the opening is $0.8 \mathrm{~mm}$ large, and they have already shown penetrability, the actual stress area of the blade is reduced, the local stress increases, and the alternating stress amplitude value will inevitably increase after the deterioration of the operation condition (the vibration of the shafting increases sharply after the occurrence of the first broken piece). In addition, there are corrosion pits on the upper surface to form the stress concentration, which are the total of these factors. Under the same action, a large number of secondary cracks are inevitable. The upper and lower surface cracks finally intersect and form a through crack. No matter the crack originates from the upper surface or the lower surface of the blade, it starts from the corrosion pit and extends in the opposite direction. Most of the cracks are along the original austenite grain boundary.

\subsection{Fracture surface analysis}

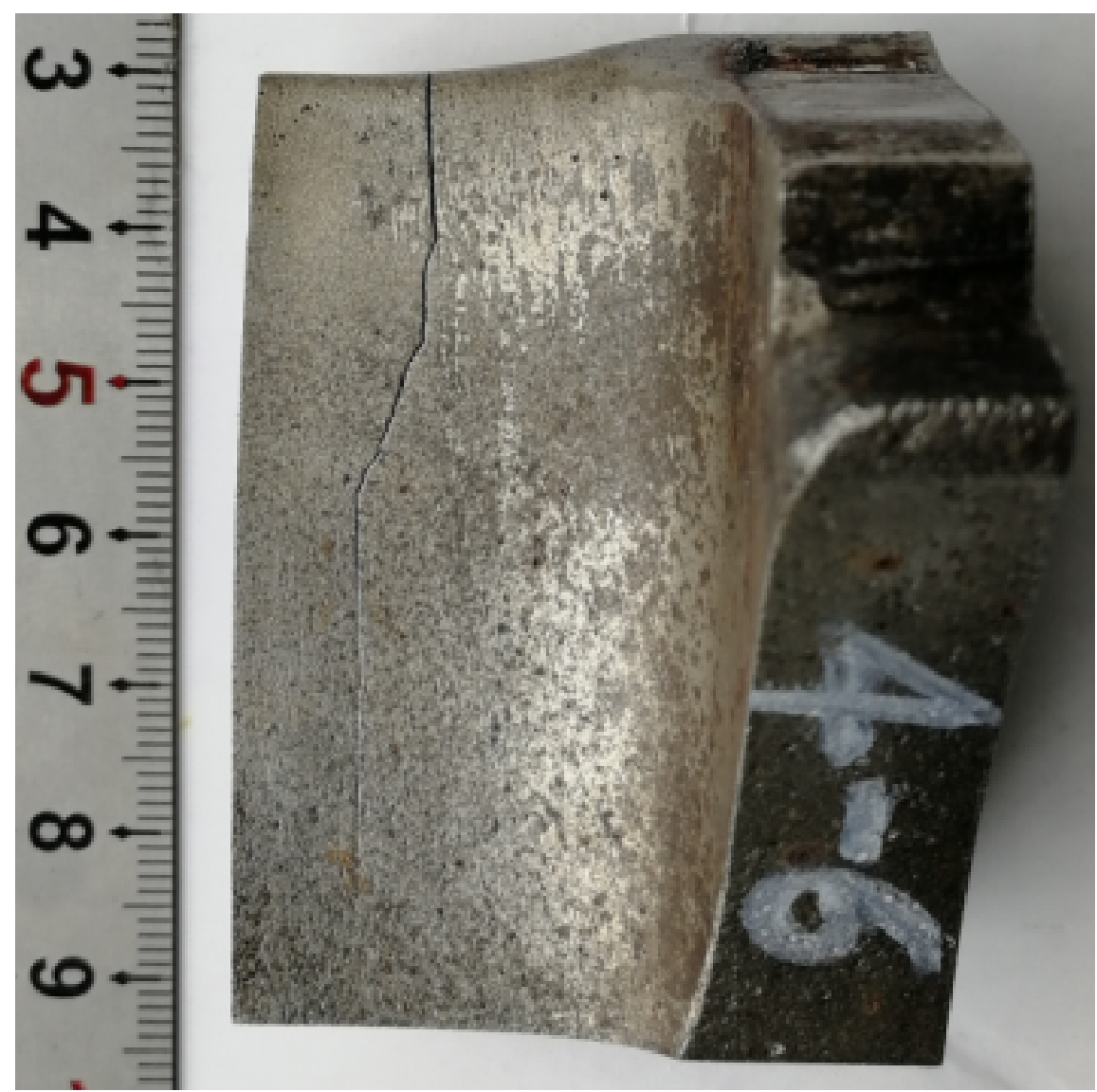



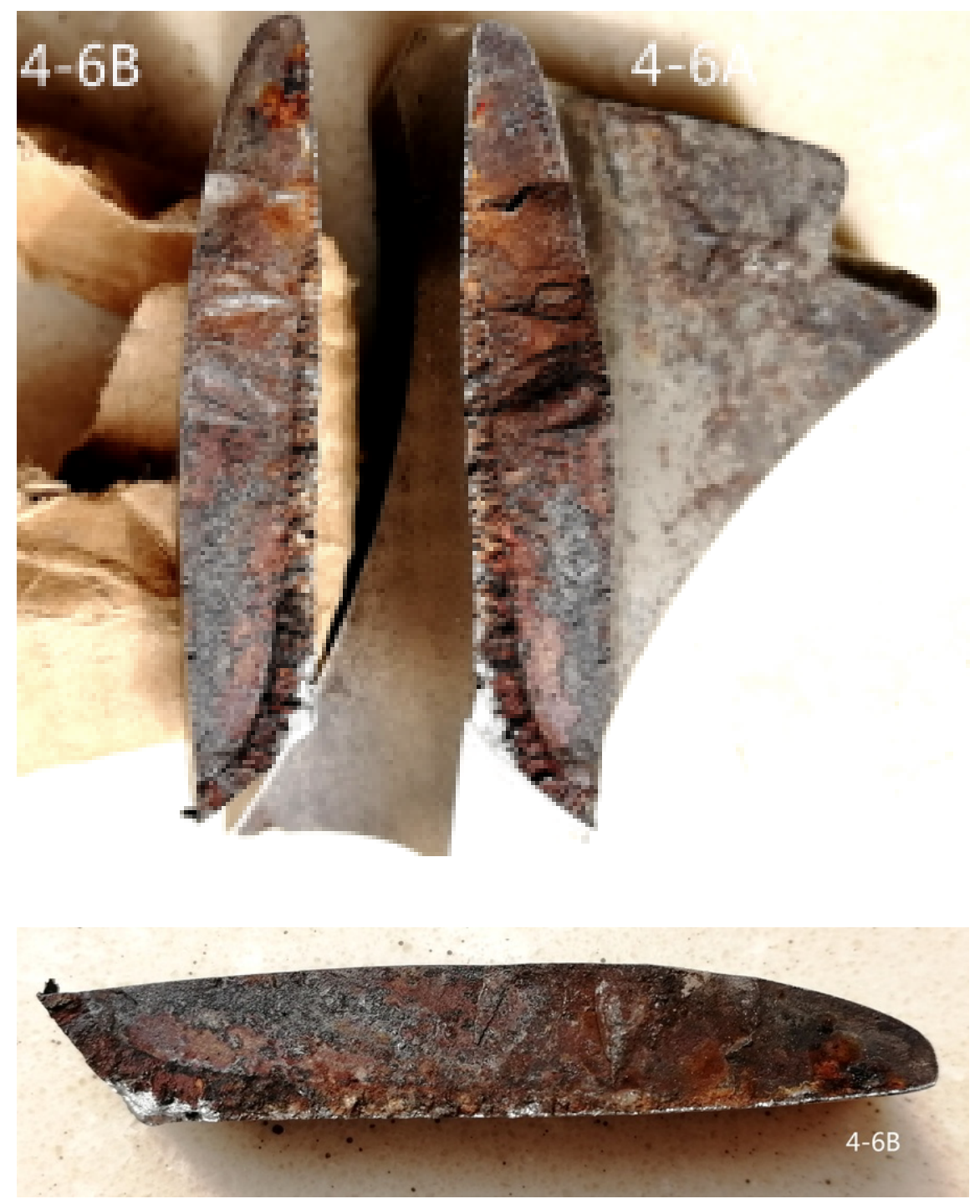

Fig. 10 Original surface not cleaned (after fracture opening)

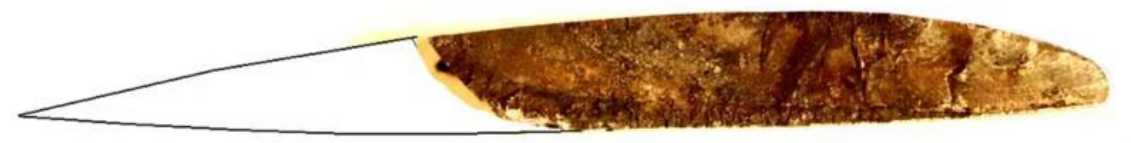

Fig. 11 The fracture after cleaning

\subsubsection{Macro Fracture Analysis}

Three kind of cracks were found in the 4\#blade: near the root, middle and near the variable cross-section of the top. 4-6 cracks were taken as the research object.

As shown in Fig. 10, the crack length of sample 4-6 is 56mm, showing penetrability, and the crack direction is perpendicular to the main stress direction. $4-6 \mathrm{a}$ and $4-6 \mathrm{~b}$ fractures were obtained after opening along the 
crack, among which 4-6b fractures were analyzed macroscopically after cleaning corrosion products. Through the observation of stereoscope and magnifying glass, the origin area, expansion area and instantaneous fracture area of the cleavage pattern can be clearly defined. The whole fracture surface is relatively flat and smooth, without obvious macroscopic plastic deformation.

As shown in Fig.11, the fracture crack origin area is located on the back arc surface about 20 mm away from the steam inlet side.The surface is rough and grainy, and there are a lot of small corrosion pits on the outer surface of the metal in the source area at low magnification. The crack propagates radially from the center of the source region to the center of blade, forming a relatively bright propagation region. It is found that there are many concentric arc lines (shell pattern) perpendicular to the crack propagation direction. It is the trace of plastic deformation along the line before the crack transient, and it is also the most basic macroscopic feature of the fatigue fracture. It can be concluded that there is no obvious stress concentration in the fracture. With the local change of crack growth direction, there are many radial fatigue steps which are perpendicular to the fatigue arc, which are the macroscopic plastic deformation traces left by the intersection of two different height fatigue cracks. Before fracture cleaning, it was observed that there was obvious corrosion product coverage in the source area and expansion area (as shown in Fig. 13). When the crack propagates to the vicinity of the inner arc through the center, an arc instantaneous fracture zone with a length of $50 \mathrm{~mm}$ and a width of less than $3 \mathrm{~mm}$ appears. The surface is gray and rough fibers, which is shown as a shear oblique fracture generally in the instantaneous fracture zone of ductile materials. It is worth noting that the area of the instantaneous fracture zone is small, which does not cause the blade fracture to fly off. The crack propagation direction is generally from the back arc to the inner arc surface along the thickness direction. The instantaneous fracture zone is generated when the critical size in the thickness direction is reached.Because the area of the extended zone is much larger than that of the transient breaking area(Fig.11), it can be inferred that the nominal stress of the fracture is relatively low.

\subsubsection{Micro fracture analysis}

The micro analysis of 4-6b fracture was carried out by SEM / EDS after confirming the basic situation of low power macro fracture.

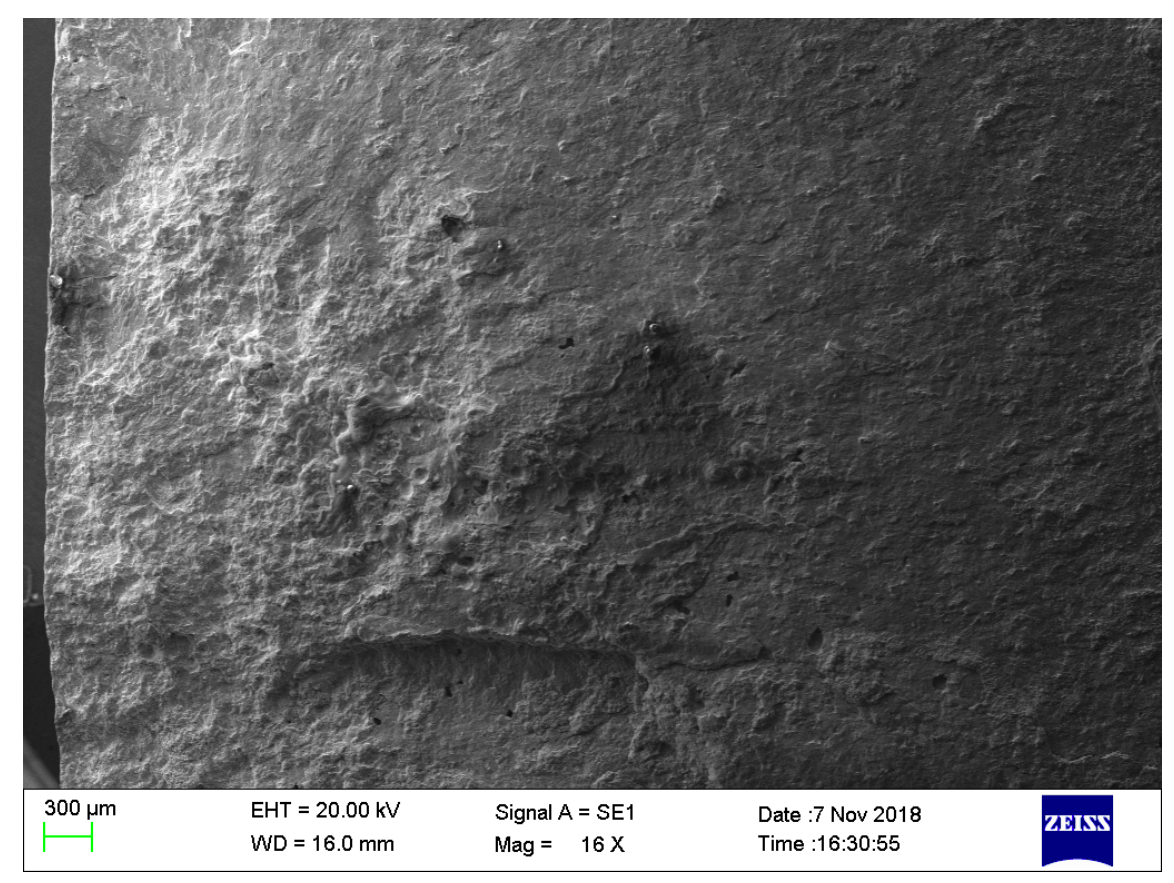




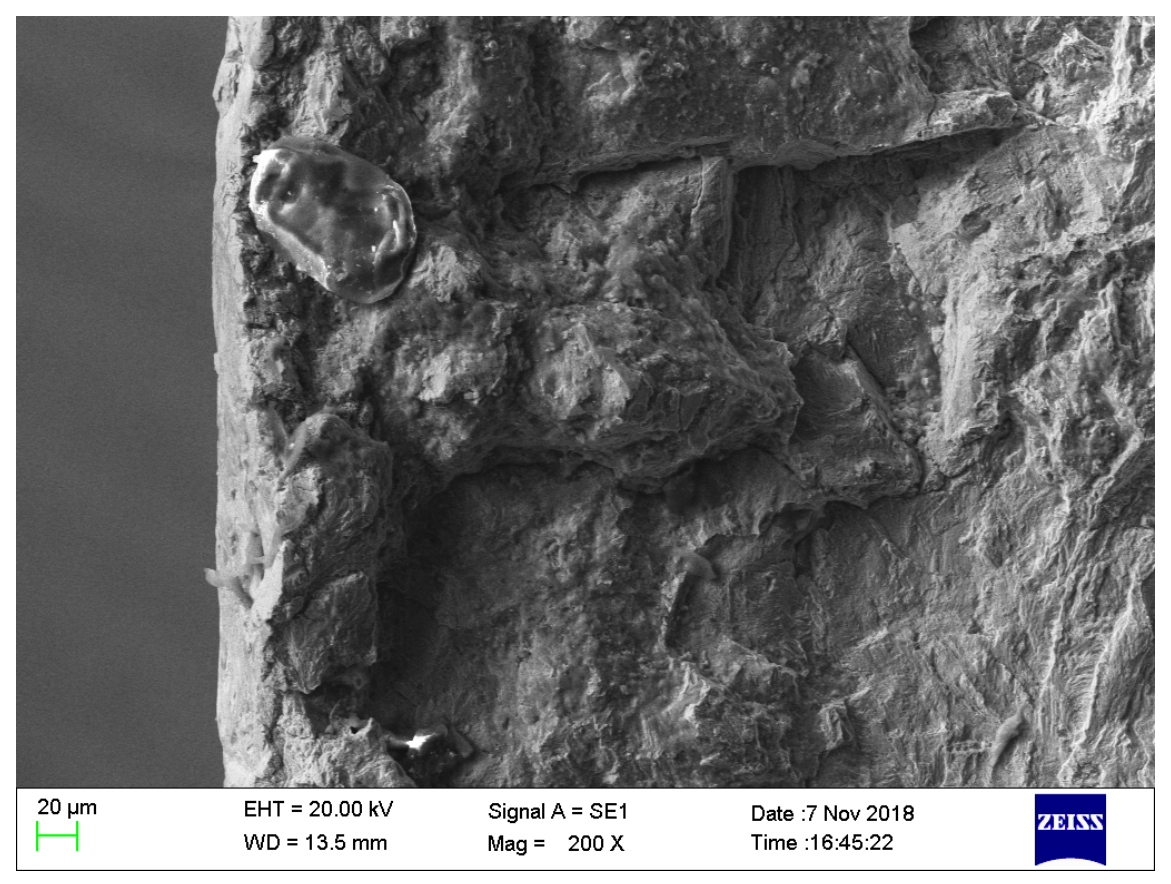

Fig.12 Morphology of crack origin area

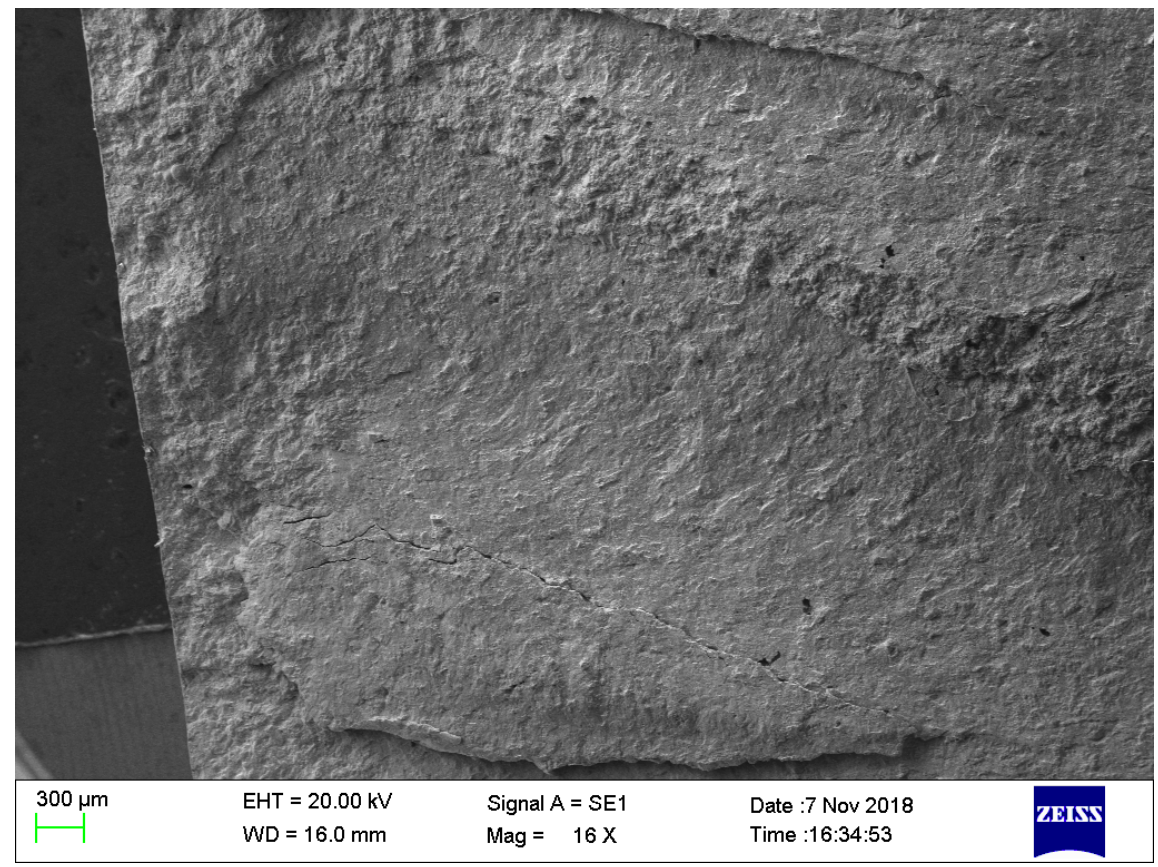




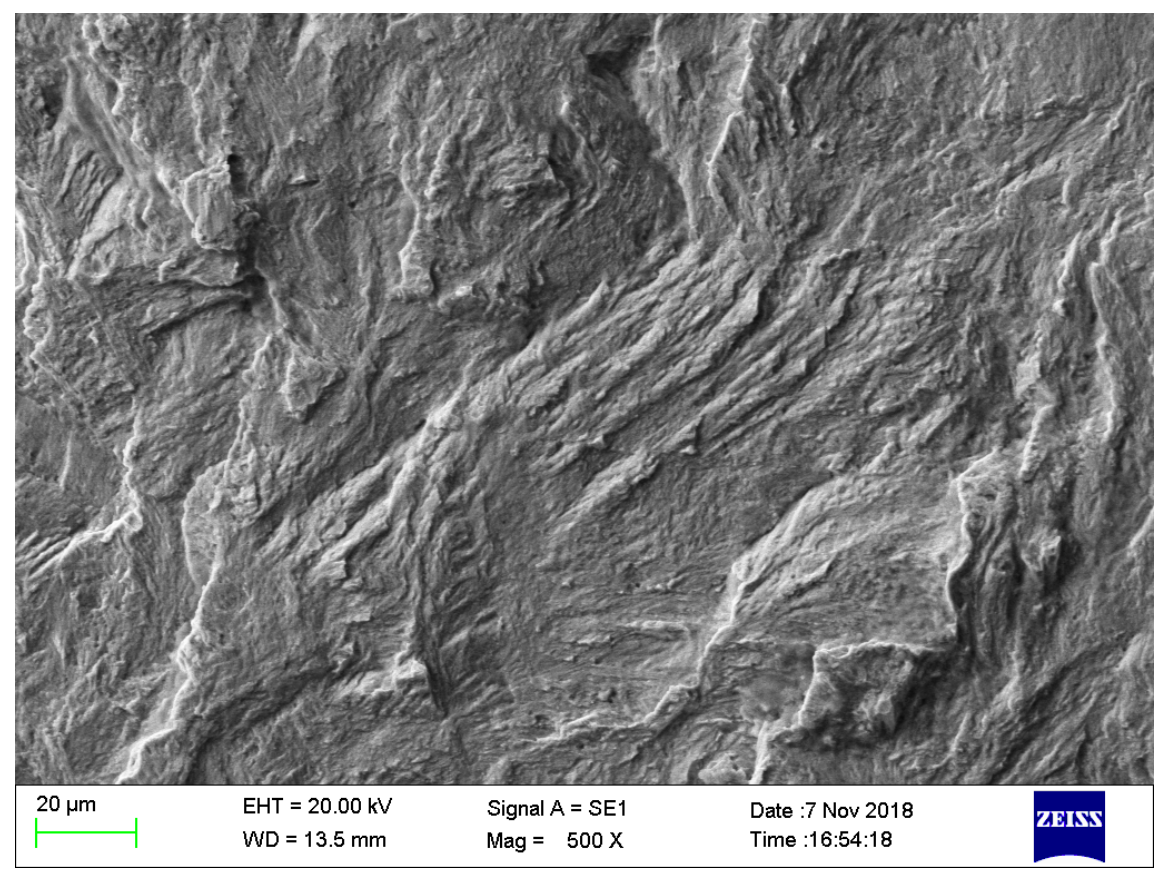

Fig.13 Crack growth zone with corrosion fatigue striae

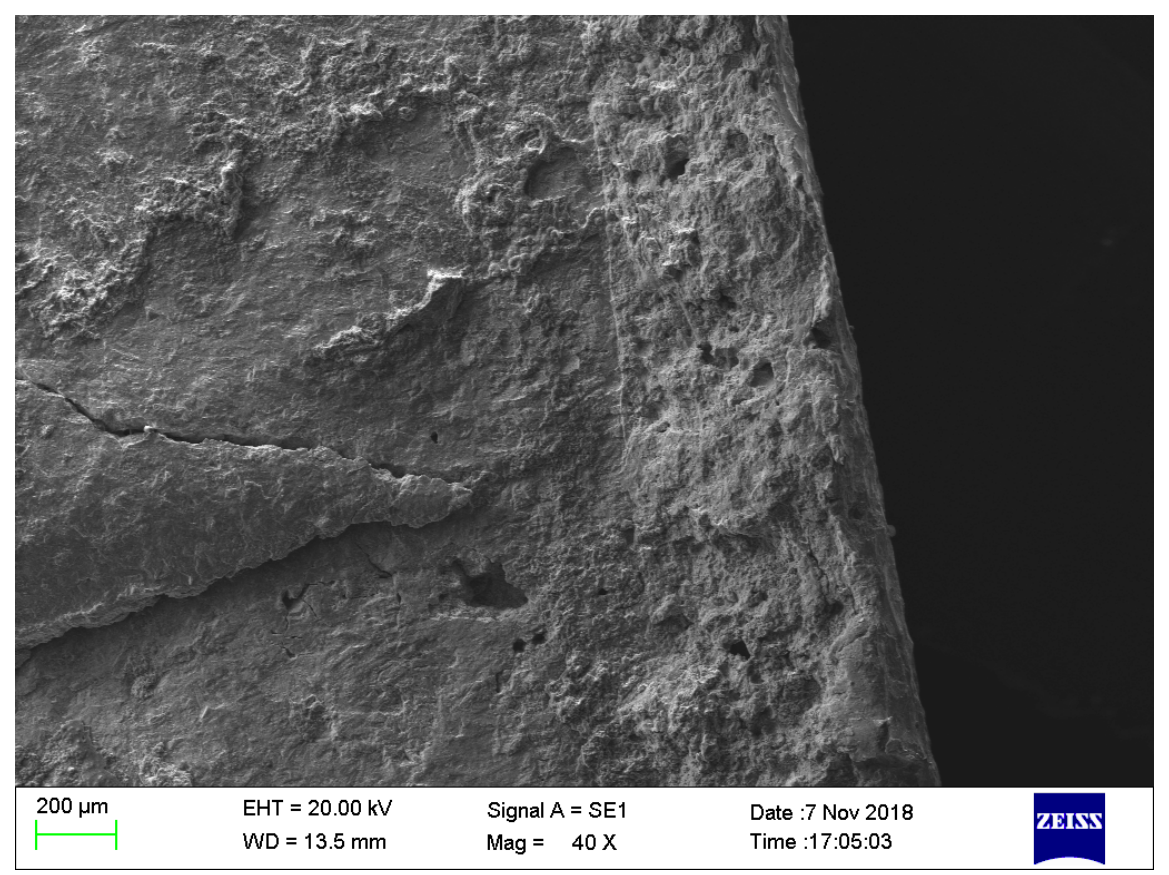




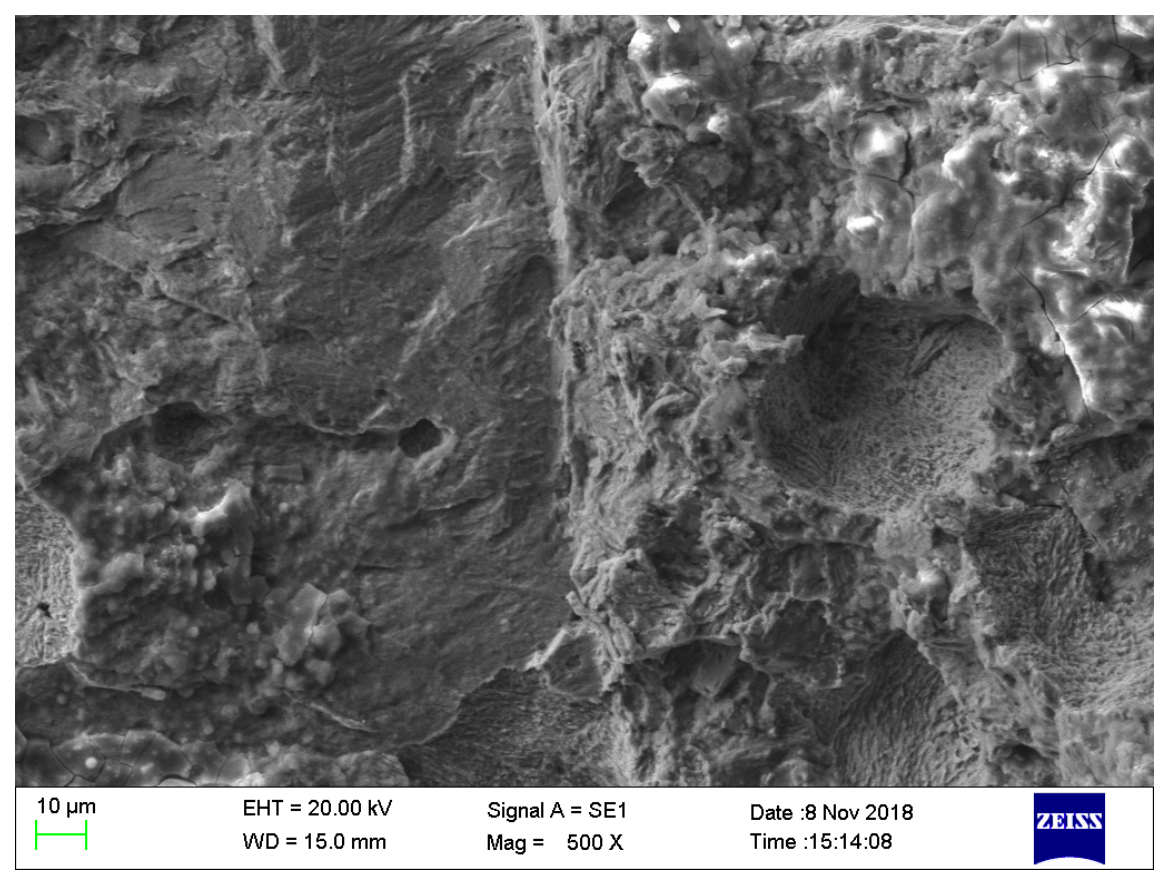

Fig.14 Instantaneous fracture area

As shown in Fig.12, the surface of the origin area is rough, and the striation is generally divergent, showing the micro morphology of cleavage. The red circle is the crack origin location.

The surface of the expansion area is bright (Fig. 13), showing river pattern, which is quasi cleavage micro morphology with obvious stripe fatigue striae.

The surface of the instantaneous fracture area is rough (Fig. 14), where the crack finally breaks rapidly, with many tear marks and a small amount of dimples, showing the micro morphology of quasi cleavage.

It can be concluded that the fracture is fatigue fracture.

\subsection{Analysis of Corrosion Products}

EDX-7000 X-ray fluorescence analyzer(XRF) was used to analyze the corrosion products in many parts of the blade. Sample 4-5 was the uncracked part, 4-6 was the section after the crack was opened, and 4-7 was the sample near the crack. The results are shown in the table below.

Table2 Chemical composition of four parts (mass\%).

The results show that the corrosion products of the four parts, and contain a certain amount of $\mathrm{Si}, \mathrm{Ca}, \mathrm{S}$, $\mathrm{Cl}, \mathrm{K}$ elements. There are $\mathrm{Cl}$ elements in corrosion pits and cracks.

Note: The cross section is obtained by pulling the sample along the crack. The elements before $\mathrm{Na}$ in the periodic table of chemical elements cannot be detected in virtue of limited by equipment performance, such as $\mathrm{C}, \mathrm{H}, \mathrm{O}, \mathrm{Na}$. Na is not detected, which does not mean that Na does not exist.

\subsection{Water quality analysis}

On November 1, 2018, some water samples of NO.1 unit were collected on site for analysis, and only chloride ion content analysis was conducted. The sampling parts are as follows: Water sample at economizer inlet; Main steam outlet steam; Water sample at condensate outlet; Water sample at condensate polishing outlet.The chloride ion content of all parts meets the requirements of operation and maintenance manual for 
fine treatment of power plant and GB/T 12145-2016 Water and steam quality standard for thermal power generating units and steam power equipment $(<1 \mu \mathrm{g} / \mathrm{L})$.

\section{Analysis and discussion}

According to the test results, the mechanical properties and chemical composition of the blade meet the requirements of the standard. The metallographic structure is low carbon martensite + dispersed intermetallic strengthening phase, and the metallographic structure is normal. From the metallographic structure of the crack section, it can be seen that most of the cracks originate from the corrosion pits on the blade surface (as shown in the Fig.8,9). The main cracks originate from the inner arc and propagate to the center, while the other secondary cracks originate from the corrosion pits on the outer arc and propagate to the center. Most of the cracks in the origin region propagate along the grain. The macro morphology of blade fracture can be clearly divided into fracture source region, crack growth region and instantaneous fracture region. There are shell like patterns in the crack growth area and shear lip shape in the $45^{\circ}$ direction in the instantaneous fracture area, which is a typical fatigue fracture morphology. According to XRF analysis, there are a lot of corrosion products, many secondary cracks, and mud like patterns in the fracture area, and there are corrosion sensitive elements such as $\mathrm{S}, \mathrm{Cl}$ which indicates that the turbine blade fracture belongs to a typical corrosion fatigue fracture.

During the operation of the last stage blade, when the impeller rotates, there are two forces acting on the blade: one is the centrifugal force generated by the mass of the blade itself, the shroud and the drawing mass; the other is the steam flow force generated by the high-speed steam flow through the blade channel. Generally, the centrifugal force not only produces tensile stress but also bending stress in the moving blade because the penetration line of the centrifugal force acting point does not pass through the center of gravity of the cross section for calculation through the blade. The steam force acting on the blade is composed of two parts: one does not change with time, and the other changes with time. Among them, the component that changes with time will cause the exciting force of the blade. Centrifugal and steam forces may also cause torsional stresses in the blades. The exciting force causes forced vibration and even resonance, which makes the alternating stress of the turbine blade increase sharply ${ }^{[9]}$. Under the action of periodic alternating stress caused by the above-mentioned multiple stresses, high cycle fatigue crack on blade is created,then gradually expands, and finally breaks due to insufficient strength. The vibration intensified sharply and the impact of the broken blade accelerate the fracture of the remaining blades while the rotor dynamic balance is damaged after one blade breaks.

In addition, the content of chloride ion, calcium and silicon in the steam exceed the standard due to the unstable quality control of steam water. The saturated steam or even wet steam is finally transformed with the gradual expansion of steam whose pressure and temperature decrease. The various ions which corrode nearby parts finally gradually precipitates on the last several stages of blades while the partial pressure of various ions in the steam changes. In particular,chloride ions do great harm to stainless steel. The surface damage (corrosion pit) of the blade caused by corrosion not only destroys the hardened layer, but also forms the crack source, which provides conditions for the generation of cracks. However, the alternating stress is the stress state that the blade must bear. Under the joint action of the alternating stress and the corrosive environment, the cracks are formed and continue to expand, which eventually leads to the blade fracture.

The detailed mechanism of crack formation is analyzed as follows.

Blade cracking originates from corrosion pits on blade surface or water erosion on blade edge. As a result of water erosion, a sharp groove which changes the stress state of the blade surface is formed at the edge of the blade, and makes the crack appear and expand more easily at this position. Pitting is considered to be the precursor of corrosion fatigue damage again and again, which has been proved by many blade failure analysis ${ }^{[10-15]}$. Pitting not only reduces the actual strength of blade, but also leads to stress concentration, which can become the core of crack in the range of low cycle stress. The formation of corrosion pit begins 
with pitting caused by chloride ion. Chloride ion pitting can be divided into two stages: pitting nucleation stage and pitting growth stage. There are two theories of pitting nucleation, that is, the theory of passive film destruction and the theory of adsorption ${ }^{[16]}$. According to the failure theory of passivation film, it is most likely to penetrate the tiny pores in the oxide film and reach the metal surface, and interact with the metal to form a soluble compound due to the small radius and strong penetration ability of chloride ion so that the structure of the oxide film changes and the metal produces corrosion. According to the adsorption theory, the fundamental reason why chloride ion destroys the oxide film is that chloride ion has a strong ability to be adsorbed by metal, and they are preferentially adsorbed by metal, and oxygen is discharged from the metal surface. Because oxygen determines the passivation state of the metal, chloride ion and oxygen compete for the adsorption point on the metal surface, and even can replace the passivation ion in the adsorption to form chloride with the metal. The adsorption of chloride on the metal surface is not stable, forming soluble substances, which leads to the acceleration of corrosion.

Once pore erosion is formed, it develops rapidly, and there are many models of pore erosion development. It is generally recognized that acidification autocatalytic process occurs in the pores. Once the pitting is formed, the external and internal reactions of the pitting are different. The metal in the hole is in the active state (the potential is negative) and becomes the anode. The metal outside the hole is in the passive state, and the potential is positive and becomes the cathode. An activation passivation micro galvanic corrosion cell is formed inside and outside the hole.

Due to oxygen enrichment outside the pore, cathode reaction occurs:

$\mathrm{O}_{2}+\mathrm{H}_{2} \mathrm{O}+4 \mathrm{e}-4 \mathrm{OH}^{-}(1)$

Anode reaction in the hole:

$\mathrm{M}-\mathrm{M}^{\mathrm{n}+}+$ ne $(2)$

Due to the increase of $\mathrm{pH}$ at the orifice, the secondary reaction of metal ions takes place, taking $\mathrm{Fe}^{2+}$ as an example,

$\mathrm{Fe}^{2+}+2 \mathrm{OH}^{-}-\mathrm{Fe}(\mathrm{OH}) 2(3)$

$\mathrm{Fe}(\mathrm{OH})_{2}+2 \mathrm{H}_{2} \mathrm{O}+\mathrm{O}_{2}-4 \mathrm{Fe}(\mathrm{OH})_{3}(4)$

The iron hydroxide formed by the reaction is deposited on the orifice. As the corrosion proceeds, the $\mathrm{pH}$ outside the orifice increases gradually, and the rust layer and the scale layer together accumulate in the crater to form an occluded battery, which hinders the ion migration, finally form oxygen concentration cell. Because the metal ions in the pore are not easy to diffuse outwards, resulting in the increase of cations. In order to maintain the electrical neutrality, the $\mathrm{Cl}^{-}$ions outside the pore migrate to the pore, and the $\mathrm{Cl}^{-}$ concentration inside the pore increases. Hydrolysis of metal ions in the pores results in serious acidification in the pores, which in turn causes more $\mathrm{Cl}^{-}$migration and acidification. The autocatalytic process of block cell is formed.

$\mathrm{M}^{\mathrm{n}+}+\mathrm{nH}_{2} \mathrm{O}-\mathrm{M}(\mathrm{OH})_{\mathrm{n}}+\mathrm{nH}^{+}(5)$

It can be said that there is a linear relationship between the pitting potential and the concentration of the aggressive ion, as it is also reported by other authors. Eq. (6) is given based on their works and describes this linear relationship ${ }^{[17]}$ :

$E_{\mathrm{pit}}=A-B \log C_{x}(6)$

where $A$ and $B$ are constants, $C_{x}$ is the concentration of the aggressive ion and $E$ pit is the pitting potential.

The increase of pitting depth mainly depends on the positive dissolution of metal in the pit. The higher the current density of anodic dissolution is, the faster the anodic dissolution speed is, the larger the corrosion pit is. In the above analysis, the blade is subjected to tension, bending, torsion, exciting force and other complex stresses. The influence of complex stress on the current density of anodic dissolution can be expressed as 
the sum of the change of internal energy caused by the anisotropic stress and the change of enthalpy caused by the plastic deformation. Under the action of complex load, the current density of activation dissolution of metal can be expressed as a function of complex stress state ${ }^{[18]}$ :

$$
\begin{array}{r}
i=i_{0} \exp \left(\frac{G}{\mathrm{RT}}\right) \\
=i_{0} \exp \left[\frac{1}{\mathrm{RT}}\left(\frac{M(1-2 v)\left(\sigma_{1}+\sigma_{2}+\sigma_{3}\right)}{3 E \rho}+\eta \frac{\mathrm{Mn}}{\rho} \frac{\sigma_{1}^{n+1}+\sigma_{2}^{n+1}+\sigma_{3}^{n+1}}{P^{n}(1+n)}\right)\right](7)
\end{array}
$$

$i$ is the current density of activation dissolution , $E$ is the modulus of elasticity, $P$ is the pressure, $\sigma_{1}, \sigma_{2}, \sigma_{3}$ is the main stress, $\nu$ is the Poisson's ratio, $\rho$ is the density of metal electrode, $\eta$ is the percentage of plastic strain energy density stored in metal.

From the above formula, it can be seen that the larger the complex load is, the greater the current density of anodic dissolution at the bottom of the pit is, the faster the anodic dissolution rate of the pit is, and the larger the pit is. According to fracture mechanics, the size of corrosion pit directly affects the threshold strength factor and critical cracking stress.

The relationship between crack stress field intensity factor,stress and crack half length:

$K=Y \sigma(\pi \alpha)^{2}(8)$

Threshold nominal stress range for crack elongation ${ }^{[19]}$ :

$\sigma_{t h}=\frac{1}{\mathrm{Y} \cdot \sqrt{\pi}} \frac{K_{t h, l c}}{\sqrt{l+l_{0}}}(9)$

$K_{t h, l c}$ is the threshold stress intensity factor range for long cracks, $\mathrm{Y}$ is a geometry factor, 1 is the crack length and $l_{0}$ is a hypothetical "intrinsic" crack length given by:

$l_{0}=\frac{1}{\pi}\left(\frac{K_{t h, l c}}{\sigma_{0} Y}\right)^{2}(10)$

It was found ${ }^{[20,21]}$ that using conventional solutions for the geometry factor according to the pit shape (e.g. the solution for a semi-elliptical crack provided by Newman and Raju $\left.{ }^{[22,23]}\right)$ leads to highly conservative results (overestimation of up to 40\%). Therefore, Eqs. (11) and (12) were evaluated according to extensive fatigue results. Following equations were suggested for the threshold nominal stress range $\sigma_{\mathrm{th}}$ :

$\sigma_{\mathrm{th}}=\frac{1}{0.42 \cdot \sqrt{\pi}} \frac{K_{t h, l c}}{\sqrt{a+a_{0}}}(11)$

$\sigma_{\mathrm{th}}=\frac{1}{0.65 \cdot \sqrt{\pi}} \frac{K_{t h, l c}}{\sqrt{c+c_{0}}}(12)$

$K_{\mathrm{th}, \mathrm{lc}}$ : threshold stress intensity factor range for long cracks,

$\sigma_{\text {th }}:$ threshold nominal stress range for crack elongation

Y: geometry factor

l: crack length

$1_{0}$ : hypothetical "intrinsic" crack length

a,c: $\mathrm{a}$ is the corrosion pit depth and $\mathrm{c}$ is the half corrosion pit width $\left(\mathrm{a}_{0}\right.$ and $\mathrm{c}_{0}$ are calculated according to Eq. (12)).

It can be seen from the above formula that crack growth is closely related to stress, depth and width of corrosion pit. The critical cracking stress decreases when the width a and depth c increase. As the width and depth of the corrosion pit increase, the critical stress decreases and the blade cracks more easily.To sum up, on the one hand, the corrosion pit which becomes the crack source under the external conditions of complex alternating stress formed by tensile force, bending force, torsion force and exciting force forms, widens and 
deepens under the action of $\mathrm{Cl}^{-}$; on the other hand, the complex alternating stress directly promotes the crack growth until the fracture failure.

It has been proposed by some authors ${ }^{[24]}$ that laser cladding of alloy elements which were a mixture of $\mathrm{Cr}, \mathrm{Ni}, \mathrm{Co}$ and $\mathrm{W}$ powder on the surface can improve the corrosion cracking resistance of blade surface. After laser alloying, the surface layer was denser and the grain refined, while the microhardness of the surface(average 610HV0.2) was about one times higher than that of the substrate material (330HV0.2). The friction coefficient of the laser-alloyed 17-4PH layer was much lower than that of the substrate.

\section{Conclusions and recommendations}

The metallographic structure composed of low carbon martensite + dispersed intermetallic strengthening phase is normal. It can be seen that the crack originated from the corrosion pit on the inner arc surface .

The fracture of the turbine blade is a typical corrosion fatigue fracture. The local point corrosion caused by steam containing $\mathrm{Cl}^{-}, \mathrm{S}^{2-}, \mathrm{K}^{+}$etc. occurs on the blade, forming a corrosion pit as the corrosion fatigue source. At the same time, the complex periodic alternating stress is formed due to the tension, bending, torsion, exciting force of the blade, resulting in high cycle fatigue(HCF), and finally brought about the corrosion fatigue fracture of the turbine blade.

The formation of corrosion pits is an electrochemical process with multiple ions and is affected by complex alternating stress. On the one hand, the stress affects the corrosion process and the formation of corrosion pits by affecting the anodic dissolution. The width and depth of corrosion pits directly affect the critical stress field intensity factor and critical strength of crack. On the other hand, the complex alternating stress directly promotes the crack growth until the fracture failure after the formation of corrosion pit.

It is suggested to strengthen the control and monitoring of water quality to reduce the corrosive ions in the water; it is necessary to avoid the emergency start, emergency stop and large changes of working conditions, minimize the alternating stress and unit vibration, and finally reduce the occurrence of high cycle and low cycle fatigue during the operation process.

It is suggested that application of suitable coating or surface modification treatment for anti-corrosion and anti-fretting on blades root surface is carried out,such as the shot peening or thermal spray metal-matrix composite coatings.

\section{Acknowledgements}

This work was financially supported by the Guangxi Province's Key Project of Research and Development Plan(Gui Science AB18294005),Beibu Gulf University High-level Talent Foundation(2018KYQD26), The Basic Ability Enhancement Program for Young and Middle-aged Teachers of Guangxi(2018KY0603). We would like to thank anonymous reviewers for their helpful comments and suggestions in improving the paper.

Reference

[1] E. Poursaeidi, M. Aieneravaie, M.R. Mohammadi, Failure analysis of a second stage blade in a gas turbine engine, Eng. Fail. Anal. 5 (2008) 1111-1129.

[2] Wang Jianghong, Qi Yan, Su Hui, et al. Summary of Fatigue Fracture Failure of Power Plant Steam Turbine Blades [J]. Steam Turbine Technology 41 (1999) 330-333.

[3] B.M. Schönbauer, S.E. Stanzl-Tschegg, A. Perlega, R.N. Salzman, N.F. Rieger, S.Q. Zhou, A. Turnbull, D. Gandy, Fatigue life estimation of pitted $12 \% \mathrm{Cr}$ steam turbine bladesteel in different environments and at different stress ratios, Int. J. Fatigue 65 (2014) 33-43.

[4] Xie Jianfeng. Fracture Failure Analysis and Technical Revamping of 50 MW Steam Turbine Blades [D]. Nanjing: Southeast University, 2004. 
[5] S. Qu, C.M. Fu, C. Dong, J.F. Tian, Z.F. Zhang, Failure analysis of the 1st stage blades in gas turbine engine, Eng. Fail. Anal. 32 (2013) 292-303.

[6] Anson. Failure Analysis of Low Pressure Secondary and Last Stage (474mm) Blades of Imported 300MW and 600MW Steam Turbines. Steam Turbine Technology 44 (2002) 224-227.

[7] B.M. Schönbauer, S.E. Stanzl-Tschegg. Fatigue life estimation of pitted $12 \%$ Cr steam turbine bladesteel in different environments and at different stress ratios, Int. J. Fatigue 65 (2014) 33-43.

[8] Zhu Baotian.Research on Fatigue Life of 905mm Last Stage Blade of Steam Turbine [J], China Electric Power 35 ( 2018)10-12

[9] Zhang Yuan, Fang Yi. Fracture Failure Analysis of Steam Turbine Blades in a Power Plant [J], Physical and Chemical Inspection 55 (2019)474-477.

[10] Wu Yukun, Zhou Jingen. Steam Turbine Blade Common Failure Mode and Research Status [J], Steam Turbine Technology 37 (1995)235-238

[11] A. Turnbull , S. Zhou.Comparative evaluation of environment induced cracking of conventional and advanced steam turbine blade steels. Part 2: Corrosion fatigue,Corrosion Science,53 (2011) 503-512.

[12] Mingxia Liua, Fei Ma,Experimental investigation of failure behavior of the cracked 17-4PH steel blades in a top gas energy recovery turbine. Engineering Failure Analysis 105 (2019) 545-554.

[13] Alyona Bashir.Corrosion fatigue crack propagation rates for steam turbine blade $13 \%$ Cr steels.Solid State Phenomena, 227, pp 7-10.

[14]D. N. Adnyana, Corrosion Fatigue of a Low-Pressure Steam Turbine Blade. J Fail. Anal. and Preven 18 (2018)162-173.

[15] C.R.F. Azevedo,A.Sinatora,Erosion-fatigue of steam turbine blades. Engineering Failure Analysis 16 (2009) 2290-2303.

[16] Li Xiaogang, Material Corrosion and Protection [M], Changsha: Central South University Press, 2009.

[17] S.Pahlavan, S. Moazen, Pitting corrosion of martensitic stainless steel in halide bearing solutions. Corrosion Science 112 (2016) 233-240.

[18] Huang Yuhui, 304 Stainless Steel Chloride Ion Corrosion Behavior Study [D]. Shanghai: East China University of Technology, 2011

[19] Bernd M. Schonbauer.The influence of corrosion pits on the fatigue life of 17-4PH, Engineering Fracture Mechanics 147 (2015) 158-175.

[20]Schonbauer BM, Stanzl SE, Perlega A, Salzman RN, Rieger NF, Zhou S, et al. Fatigue life estimation of pitted $12 \% \mathrm{Cr}$ steam turbine blade steel in different environments and at different stress ratios. Int $\mathrm{J}$ Fatigue 65(2014)33-43.

[21] Schonbauer B, Perlega A, Karr UP, Gandy D, Stanzl-Tschegg S. Pit-to-crack transition under cyclic loading in $12 \%$ Cr steam turbine blade steel. Int J Fatigue 76(2015)19-32.

[22] Newman JC, Raju IS. Analyses of surface cracks in finite plates under tension or bending loads. NASA; 1979 .

[23] Newman JC, Raju IS. Stress-intensity factor equations for cracks in three-dimensional finite bodies. NASA; 1981.

[24] Jianhua Yao, Liang Wang.Surface laser alloying of 17-4PH stainless steel steam turbine blades 40 (2008) 838-843. 